\title{
BIRD'S-NEST FUNGUS IN THE CYPRESS HILLS
}

by M. V. S. Raju and Barbara M. Ross,

University of Saskatchewan, Regina

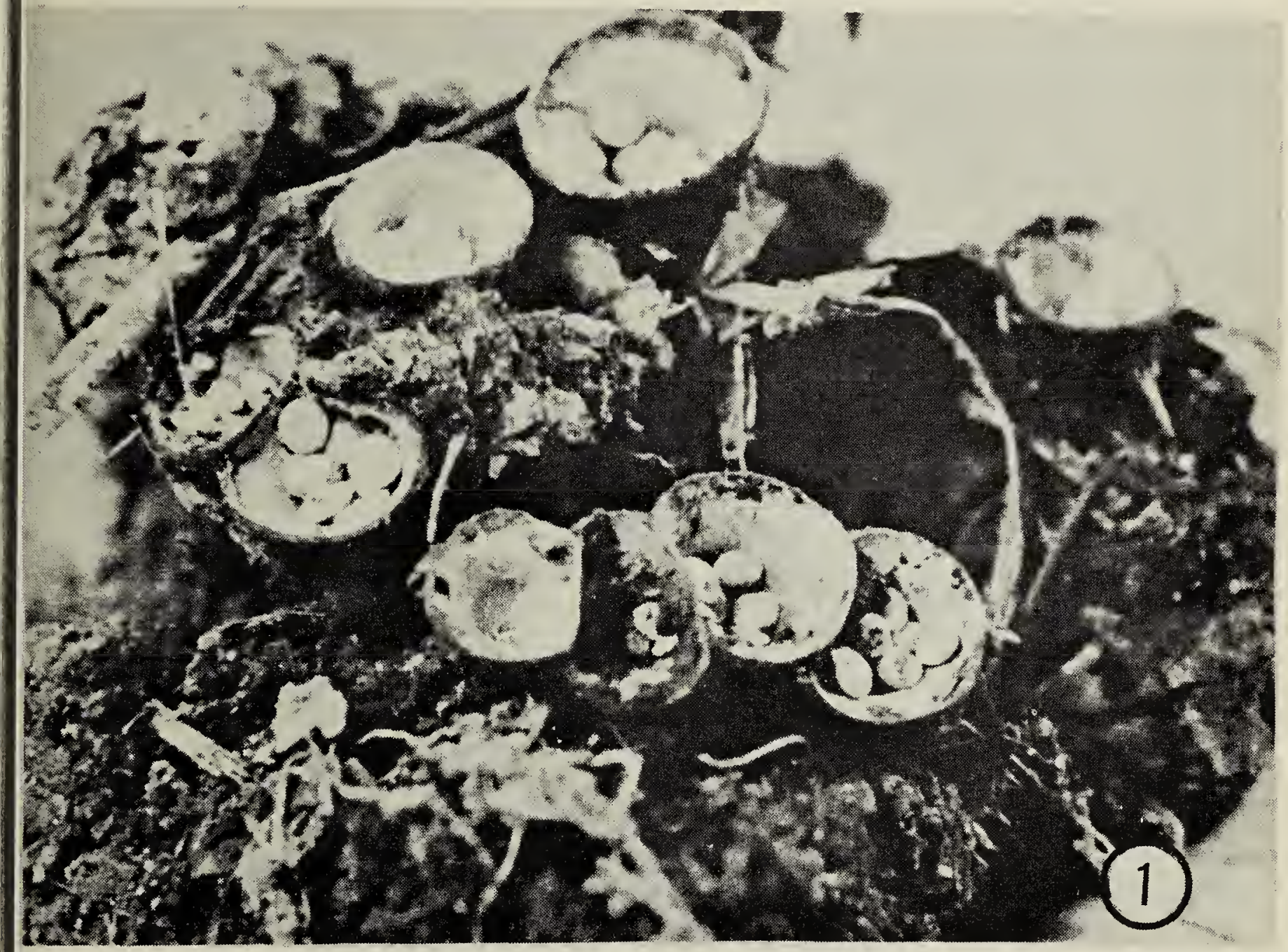

University of Saskatchewan, Regina, Photo

Fig. 1. Photograph of bird's-nest fungus Crucibulum, growing on plant and soil debris. Note peridioles (sporangioles) in the cups. Magnified X4.

During a recent visit, June 21, 1969 , to the Cypress hills in Saskatchewan, we observed a fungus belonging to the group Basidiomycetes in an area where aspen and lodge-pole pine were in abundance. This fungus was later identified as the genus Crucibulum of the order Nidulariales. Sevcral individuals of this fungus showing various stages of growth were found on decayed wood and on other plant and soil debris (Figs. 1, 2, 4). These minute forms varied considerably in height from $2-8 \mathrm{~mm}$.

Crucibulum and also other members of the Nidulariales are commonly called bird's-nest fungi, because the mature plant body (fruiting body) appears like a bird's nest with a shallow cup in which lie white lentilshaped structures that resemble bird's eggs (Figs. 1, 2, 5). These egg-like structures are known as peridioles. This fungus is seldom seen in nature, but it occurs in great numbers whenever it is seen to occur in an area.

The young fruiting body arises as a small brownish, often hairy, knob and it is made up of an outer rough dark covering called the peridium which later on opens to form a cup with white inner surface. When the cup opens up, a whitish structure called the gleba is exposed (Fig. 4). The gleba on maturity produces several peridioles (Figs. 1, 2, 5). Each 
peridiole contains a large number of basidiospores; it is white and smooth on the upper side and slightly brownish and hairy on the lower side (Fig. 3). At certain stages, particularly when the peridiole is being disseminated, it shows on its lower midregion a funicular cord that terminates at the free end in a slightly expanded hapteron. In fig. 3 the hapteron of the peridiole with its long and stretched funicular cord, is attached firmly to the inner side of the cup of the fungus. If the conditions are favourable, the basidiospores enclosed in the peridiole germinate, producing a large mass of filamentuus structures or mycelia. Such mycelia further spread on the substrata such as decayed wood, etc., and subsequently develop into complex fruiting bodies of the type described before.

The peridioles of the Nidulariales are known to exhibit an interesting "splash-cup" mechanism in their dissemination. In some members, it has been demonstrated that a rain drop falling into the cup splashes the peridioles to a distance of about a meter and some rare instances to a height of 3-4 meters.

The fungus Crucibulum is essentially a tangle of innumerable delicate microscopic filaments produced by minute basidiospores. These subtle filaments undergo a series of highly complicated developmental stages that culminate in highly organized microscopic bodies that we recognize in nature as the bird's-nest fungus.

While examining the cups of Crucibulum, we observed several small green rounded bodies on their white inner walls (Fig. 5). These microscopic bodies were later identified as colonies of filaments of a green alga, Hormidium, a member of the order Ulotrichales (Fig. 6). It is an interesting association and its exact significance is not clear at present. The occurrence of this green alga only in a few cups, however, suggests that the association is accidental.
For more details of this interesting fungus and the alga, the reader may consult the following references:

Alexopoulos, C. J. 1962. Introductory mycology, 2nd ed., John Wiley and Sons, N.Y.

Bessey, E. A. 1950. Morphology and taxonomy of fungi, The Blakiston Co., Philadelphia.

Brodie, H. J. 1951. The splash-cup dispersal mechanism in plants. Can. J. Botany, 29:224-234.

Dodge, B. O. 1941. Discharge of the sporangioles of bird's-nest fungi. Mycologia, $33: 650-654$.

Fritsch, F. E. 1965. The structure and reproduction of the algae, Vol. 1. Reprint. Cambridge, England.

Smith, G. M. 1951. The fresh-water algae of the United States. 2nd ed. McGraw-Hill, N.Y.

\section{Explanation of figures on opposite page}

Fig. 2. A piece of decayed wood with fruiting bodies of the fungus.

Fig. 3. Upper and lower views of peridiole. Notice the long stretched-out funicular cord.

Fig. 4. Decayed wood with the fungus showing various stages of development. Note the three peridioles attached to the substratum.

Fig. 5. Top view of the fruiting bodies to show algal colonies and also peridioles.

Fig. 6. Enlarged view of a fragment of algal filament. Scale indicates microns.

\section{Explanation of abbreviations used in sketches}

ac, algal colonies

fc, funicular cord

$h$, hapteron

$\mathrm{p}$, peridiole

pe, peridium. 


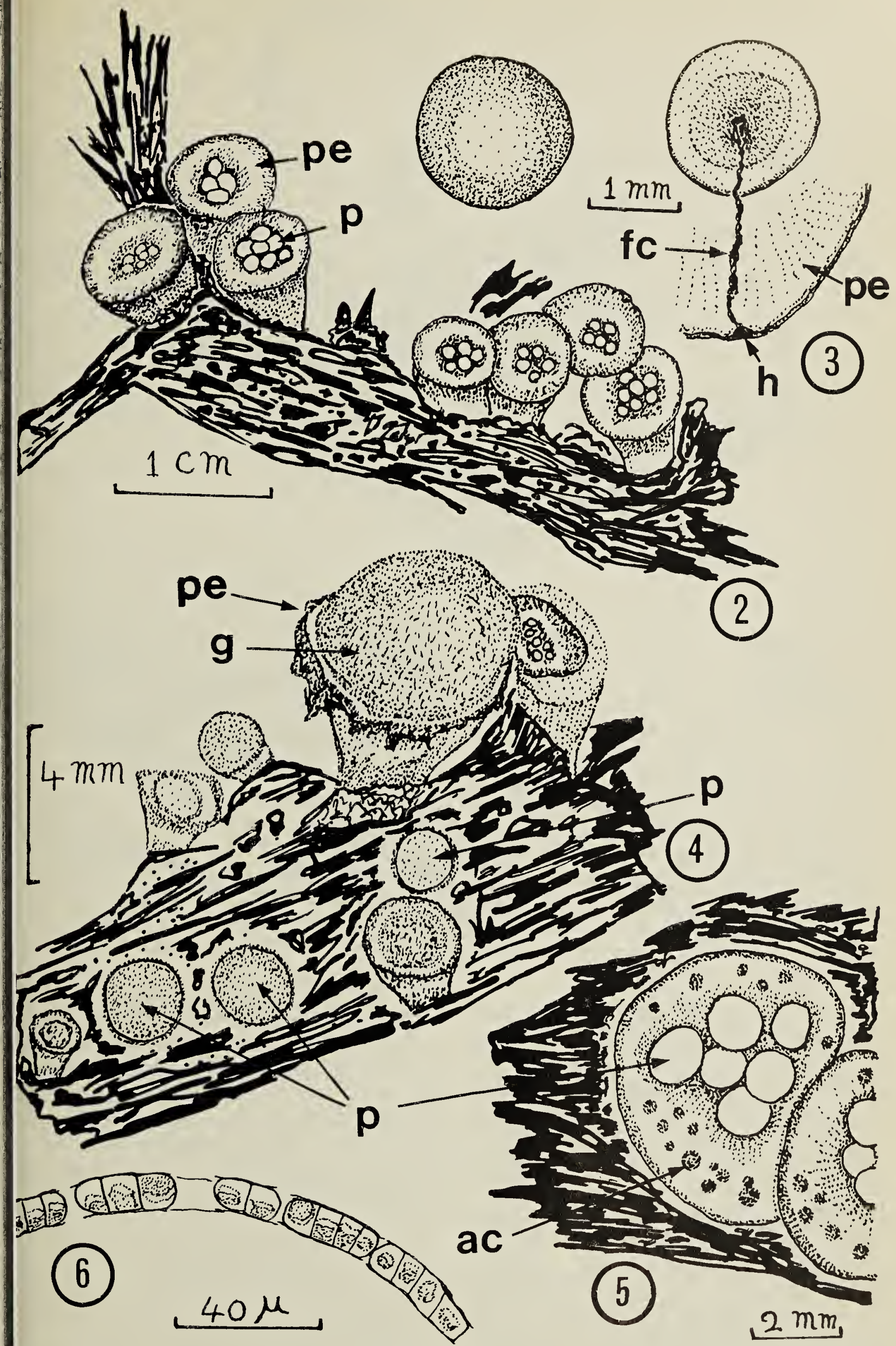

Figs. 2-6. Drawings of bird's-nest fungus. 